\title{
Monaldi cavernostomy for lung aspergillosis: A case report
}

\author{
CORNEL PETREANU ${ }^{1,2 *}$, ALINA CROITORU ${ }^{2,3}$, ALEXANDRU GIBU $^{1}$, ALEXANDRU ZARIOSU $^{1}$, \\ NICOLAE BACALBASA ${ }^{4-6 *}$, IRINA BALESCU ${ }^{7}$, CAMELIA DIACONU $^{8,9}$, OVIDIU STIRU $^{10,11}$, \\ MIHAI DIMITRIU ${ }^{4,12}$, DRAGOS CRETOIU ${ }^{13}$ and CORNEL SAVU ${ }^{1,2}$
}

${ }^{1}$ Department of Thoracic Surgery, 'Carol Davila' University of Medicine and Pharmacy, 020021 Bucharest;

${ }^{2}$ Department of Thoracic Surgery, 'Marius Nasta' National Institute of Pneumology, 050159 Bucharest;

Departments of ${ }^{3}$ Pneumology and ${ }^{4}$ Obstetrics and Gynecology, 'Carol Davila' University of Medicine and Pharmacy, 020021 Bucharest; ${ }^{5}$ Department of Visceral Surgery, Center of Excellence in Translational Medicine,

'Fundeni' Clinical Institute, 022328 Bucharest; ${ }^{6}$ Department of Obstetrics and Gynecology, 'I. Cantacuzino' Clinical Hospital,

030167 Bucharest; ${ }^{7}$ Department of Visceral Surgery, 'Ponderas' Academic Hospital, 021188 Bucharest;

${ }^{8}$ Department of Internal Medicine, 'Carol Davila' University of Medicine and Pharmacy, 020021 Bucharest;

${ }^{9}$ Department of Internal Medicine, Clinical Emergency Hospital of Bucharest, 105402 Bucharest;

${ }^{10}$ Department of Cardiovascular Surgery, 'Carol Davila' University of Medicine and Pharmacy, 020021 Bucharest;

${ }^{11}$ Department of Cardiovascular Surgery, 'Prof. Dr. C. C. Iliescu' Emergency Institute for Cardiovascular Diseases, 022322 Bucharest; ${ }^{12}$ Department of Obstetrics and Gynecology, 'Sf. Pantelimon' Emergency Clinical Hospital,

021659 Bucharest; ${ }^{13}$ Department of Cell and Molecular Biology and Histology,

'Carol Davila' University of Medicine and Pharmacy, 020021 Bucharest, Romania

Received January 22, 2021; Accepted February 22, 2021

DOI: $10.3892 / \mathrm{etm} .2021 .10389$

\begin{abstract}
Pulmonary aspergillosis in patients with respiratory failure can severely affect the pulmonary functional status and may aggravate it through pulmonary suppuration, by recruitment of new parenchyma and hemoptysis, which can sometimes be massive, with lethal risk by flooding the bronchus. The treatment consists of a combination of medical therapy, surgery and interventional radiology. In small lesions, less than $2-3 \mathrm{~cm}$, medical therapy methods may be sufficient; however, in invasive forms (larger than $3 \mathrm{~cm}$ ) surgical resection is necessary. Surgical resection is the ideal treatment; nevertheless, when lung function does not allow it, action must be taken to eliminate the favorable conditions of the infection. In such cases, whenever the lung cavity is peripheral, a cavernostomy may be performed. Four cases of lung cavernous
\end{abstract}

Correspondence to: Mr. Cornel Savu, Department of Thoracic Surgery, 'Marius Nasta' National Institute of Pneumology, Soseaua Viilor 90, 050159 Bucharest, Romania

E-mail:drsavu25@yahoo.com

*Contributed equally

Abbreviations: FVC, forced vital capacity; FEV1, forced expiratory volume (1-measured during the first forced breath); CT, computed tomography

Key words: pulmonary aspergillosis, cavernostomy, mycetoma, respiratory failure, pulmonary suppuration lesions colonized with aspergillus, in which the need for a therapeutic gesture was imposed by repeated small to medium hemoptysis and by the progression of respiratory failure, were evaluated, one of which is presented in the current study. Cavernostomy closure can be realized either surgically with muscle flap or spontaneously by scarring, after closure of the bronchial fistulas by epithelization and granulation. There were no recurrences of hemoptysis or suppurative phenomena. There was one death, a patient with severe respiratory failure caused by superinfection with nonspecific germs. However, in the case presented in this study, the patient recovered following cavernostomy, which seems to be an effective and safe method for cases in which lung resection is not feasible.

\section{Introduction}

Pulmonary aspergillosis is a lung disease secondary to the presence of a ubiquitous germ, Aspergillus fumigatus, which occurs mainly in immunodeficient individuals. Aspergillus fumigatus is often the most blamed fungus in Aspergillosis lung injuries. It is a ubiquitous germ that can be aggressive through systemic reactions, as well as local or disseminated development. There are five described anatomo-clinical forms. The allergic bronchopulmonary form involves the development of the germ in conditions of asthma or bronchiectasis with the onset of allergic immunological reactions. Another non-invasive type is the localized form of pulmonary aspergilloma, which is found in the development of mycetoma in conditions of localized pulmonary emphysema or intraparenchymal cavernous lesions, where it finds optimal conditions for development (humidity, darkness and lack of 
ventilation) (1-3). The extreme form of local invasion is chronic necrotizing aspergillosis with extensive pleuropulmonary injuries (4-6). The systemic extensive form in immunosuppressed individuals is represented by invasive pulmonary aspergillosis (7-9). A form of hypersensitivity pneumonia caused by inhalation of aspergillus particles is also described (10).

The localized form of pulmonary or chronic necrotizing aspergillosis has a high lethal potential outcome, both by progressively induced respiratory failure and by possible acute-associated complications, including pulmonary suppuration and hemoptysis. Aspergilloma usually occurs in old post-tuberculosis lung cavernous lesions $(1-5,11,12)$. Through recurrent infections with periods of pulmonary suppuration and remission, additional parenchyma is recruited with each exacerbation, functionally excluding new parenchymal areas. In addition, by releasing endotoxins, the hypertrophy of the local bronchial vascularization is stimulated until they rupture and trigger hemoptysis, a complication with high immediate lethal risk by pulmonary flooding; it exposes the lesion to superinfection (13-18).

In the case presented in this study, the patient successfully underwent cavernostomy, a potentially effective and safe method for cases with life-threatening hemoptysis in which lung resection is not feasible.

\section{Case report}

Approval for the case report was obtained from the Ethics Committee of 'Marius Nasta' National Institute of Pneumology, Bucharest, Romania (no. 152/2020). Written informed consent was signed by the patient on 13.05.2020.

A patient with low social status, former smoker with a history of left pulmonary tuberculosis, cachexia, was admitted into the Department of Thoracic Surgery, 'Marius Nasta' National Institute of Pneumology, having presented repeated mild hemoptysis in the previous 3 weeks, bronchial suppurative phenomena and worsening respiratory failure manifesting through shortness of breath and hypoxemia.

Chest X-ray revealed a left apical pulmonary cavity (Fig. 1). The chest computed tomography (CT) showed a culminal cavity surrounded by consolidation, probably due to aspergillosis infection and aspiration of blood (Fig. 2).

The bronchoscopy revealed an abnormal structure of the left upper lobe bronchus, suppurative characteristics and hemoptysis traces in the culminal bronchus. The bronchoscope reached the aspergillary cavity; it revealed $9 \mathrm{~mm}$ diameter through the upper left bronchus and culminal bronchus.

The pulmonary function test results indicated: FVC: 2.661 , $74 \%$, and FEV1: $800 \mathrm{ml}$ after antibiotic treatment. The arterial blood gas tests indicated a resting hypoxemia of $70 \mathrm{mmHg}$. Considering the results, performing lung resection was not possible due to the extremely high risks involved; therefore, another procedure was necessary.

Preoperative care included embolization of the bronchial arteries, in order to avoid hemoptysis in the perioperative period. Antibiotic and antifungal treatment regarding the suppurative phenomena was established based on the antibiogram.

The therapeutic procedure of choice was Monaldi Cavernostomy, in optimal conditions. The procedure was

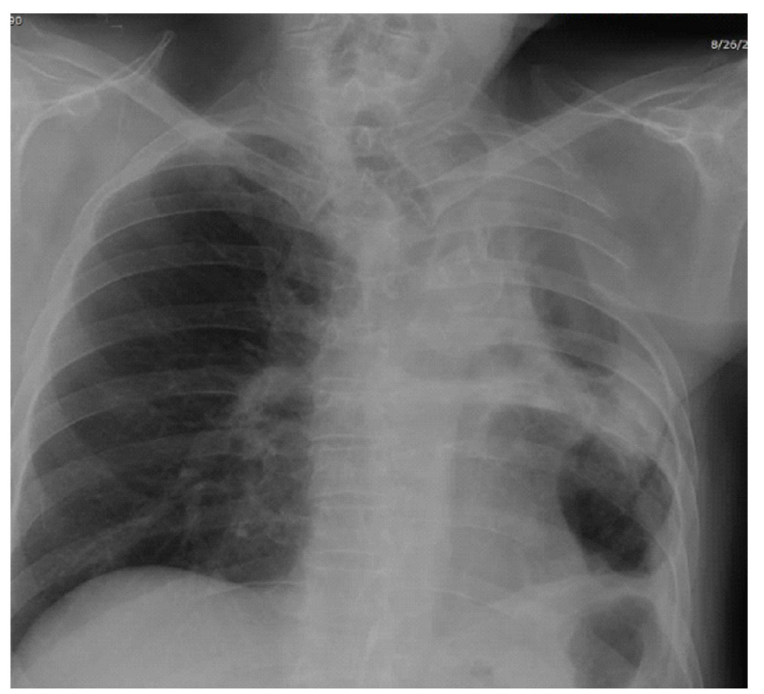

Figure 1. Radiological aspects of caverna.

carried out in the left axillary region, consisting of 4 lateral sections of the ribs resected (3-6), guided by peripheral contact of the cavern with the thoracic wall. Removal of the adjacent thickened pleura was performed, creating an opening, followed by removal of the mycetoma, cavity lavage and the identification of multiple bronchial fistulas inside the cavity (Fig. 3).

The next step was determined by musculocutaneous flap to pleuropulmonary edge suture. No per primam suture of the fistulas was intended. Slightly compressive bandage was performed to enable aerial drainage of the bronchial fistulas. Subsequently, daily dressing of the wound was practiced. Antibiotic treatment, including antifungal treatment, was maintained for 3 weeks.

Furthermore, after 3 months, muscular myoplasty was necessary in order to fill in the cavity, to favor the closure of the remaining fistulas and a reopening of the skin stoma, which had a tendency of closing.

After 1 year, the patient did not present any episode of hemoptysis or suppurative process and no progressive degradation of respiratory function. Difficulty in speaking was present in the first two months after the surgery, being ameliorated by adducting the upper limb at the level of the skin stoma, due to major air losses through the bronchial fistulas. The difficulties of local care, local dressing, initially with betadine grooming and sterile dressing were overcome in approximately 3 weeks, the patient being independent after this period.

\section{Discussion}

The diagnosis of pulmonary aspergillosis is usually based on imaging, with the typical radiological aspect of intracavitary mycetoma being the Monod sign, especially in the context of tuberculosis-related history and clinical manifestations of recurrent hemoptysis. The bronchoscopy examination often reveals chronic bronchial alterations and, through bronchial aspiration, aspergillus fumigatus is identified $(19,20)$.

The antifungal drug treatment is complementary to the surgical treatment, in order to limit the local suppurative effects (21-23). In addition, hemostatic drugs such as lysine 


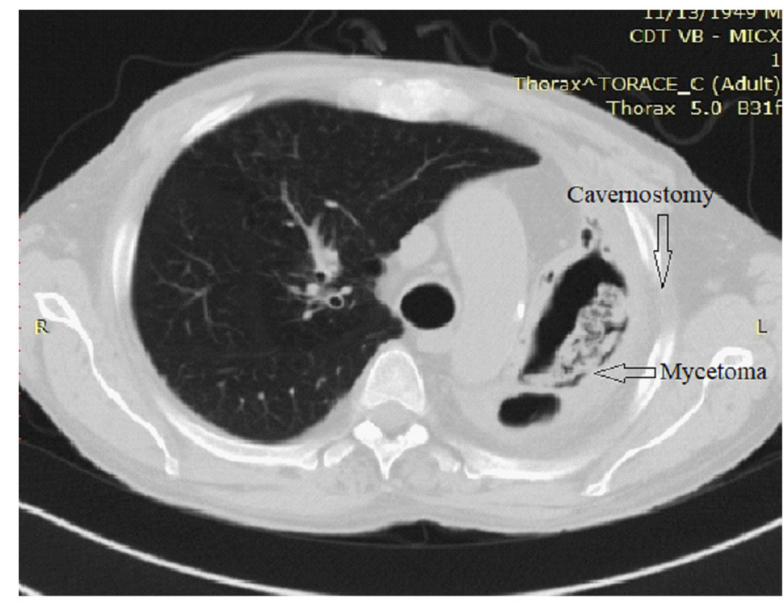

Figure 2. CT aspects of the lesion.

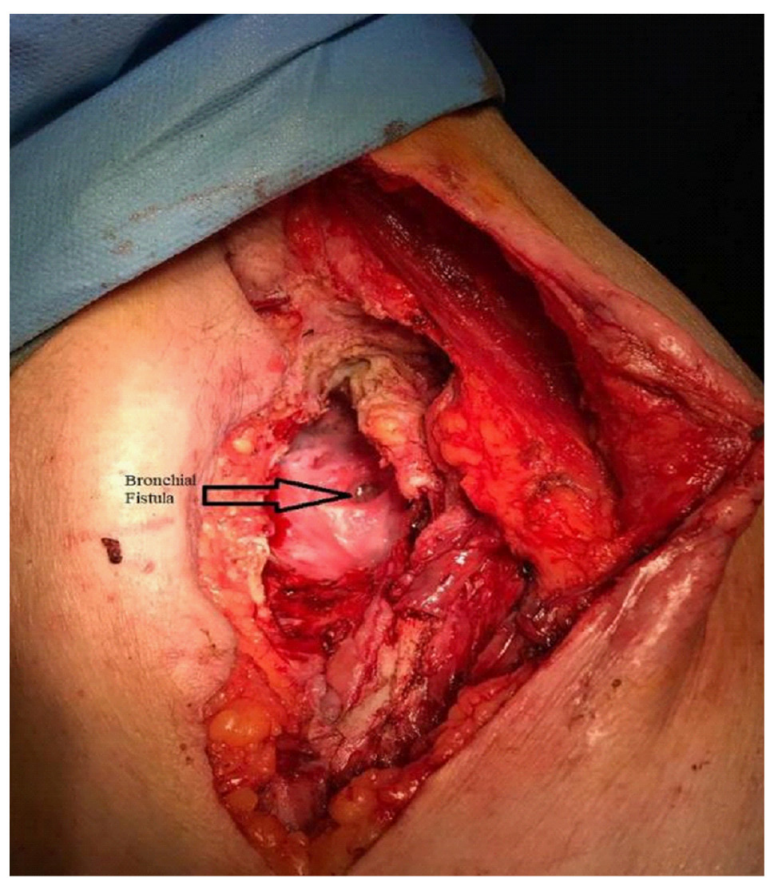

Figure 3. Intraoperatory image-cavernostomy.

derivatives type are used in order to decrease the postoperative hemorrhagic incidents, given the increased risk of bleeding by specific pleuropulmonary adhesions $(13,24-26)$.

The interventional radiology treatment, the embolization of the hypertrophied bronchial artery, has a temporary effect $(13,27)$ and it can be used preoperatively to avoid suppurative or hemoptysis perioperative episodes. Single embolization has a risk of recurrence of hemoptysis of over $50 \%$ because the environmental conditions that allowed the development of aspergilloma remain present $(13,24)$.

The treatment of pulmonary aspergilloma in a single, non-invasive form or in chronic pulmonary aspergillosis, as well as the invasive form is a combined surgical, radiological and medical treatment $(13,21-28)$. The therapeutic strategy is individualized for each patient $(2,24,28)$. The ideal treatment is surgical, by removing the pulmonary caverns or cavities with favorable conditions for fungal development, thus excluding the maintenance factors of suppurative phenomenon or recurrent massive hemoptysis $(2,28)$. In addition, adjusted procedures are recommended as much as possible, avoiding remnants of affected lung tissue.

Whenever there is a patient with pre-existing compromised lung function that makes lung resection not possible, alternative surgical solutions should be considered. The purpose is to abolish the pathological conditions for the development of this fungus, such as lung caverns or superinfected air bubbles.

Cavernostomy, which represents the conservative surgical treatment of invasive pulmonary aspergillosis, should be considered in cases with a lung function that does not allow pulmonary resection, but also in patients with comorbidities that prevent them from benefiting from major lung resections, as in pre-existing high-risk cardiovascular conditions (17,29-35). Da Silva et al (36) identified an indication for cavernostomy as the forms of chronic invasive pulmonary aspergillosis that require pleuropneumonectomy-fused intrapleurally with complete pulmonary destruction or with bilateral forms, usually occurring in immunocompromised patients or with modified clinical condition. Therefore, it can be indicated even in those with permissive respiratory function. The therapeutic objective is to abolish the conditions that lead to the development of Aspergillus by performing cavernostomy (34-36).

Cavernostomy is applied in selected cases with peripherally cavernous lesions colonized with Aspergillus, in close contact with the chest wall and its structures.

Height recommends closed drainage for 7-10 days, with intracavitary lavage with antifungals in the preoperative period (26).

It involves making an ' $\mathrm{H}$ '-shaped skin incision centered on the cavity or on the pleurotomy orifice of the previously placed pleural drainage tube. The approach site is usually axillary to the posterior axillary line for the lesions found in the Fowler segment, but also interscapular vertebral approach for posterior and even apical ones. In forms with significant lung damage and remodeling, cavitary wall exposure dictates drainage (34,37-39).

Musculocutaneous flaps are harvested and are then attached to the pleuropulmonary edges of the cavern after the resection of 2-3 costal segments and after the excision of the exposed thickened pleura. Careful ligation of the affected intercostal pedicles and careful hemostasis are practiced, given the risk of hemorrhage secondary to adhesions and local vascular hypertrophy.

The cavity is cleaned, removing the mycetoma and identifying the bronchial fistulas.

The complete excision of the exposed thickened pleura is performed while avoiding the creation of 'pockets', in order to have a maximum opening and exposure of the pulmonary cavity.

Subsequently, by daily dressing and cleaning of the cavernostoma, the granulation and epithelialization of the cavern will be stimulated. Sometimes, it is necessary to reopen the stoma due to its tendency of superficially closing. Nakada et al uses the Alexis wound retractor to avoid this issue (31). Bronchial fistulas may persist for a long time, but they eventually slowly close. The closure of the cavernostoma, a secondary therapeutic objective, can be performed surgically by myoplasty or can occur spontaneously by epithelialization $(31,33,34,40,41)$. 
Under optimal functional conditions, most authors indicate pulmonary resection as an elective treatment in invasive pulmonary aspergillosis. Cavernostomy, originally considered for tuberculosis lesions, was subsequently employed for patients with invasive pulmonary aspergillosis with borderline lung function, in whom the anesthetic-surgical risk was too high to perform lung resection.

Authors found that in the group with conservative drug treatment in symptomatic forms the results were poor, with a significant mortality rate at 12 months. Therefore, surgical treatment was imposed. It is unanimously accepted that in patients with absolute contraindication to surgery, parenteral treatment is not sufficient and it is recommended to inject intracavitary amphotericin, or saline solution, and if possible, draining the cavity under CT guidance. Complete or temporary remissions can be obtained (26).

Takahashi et al (42) presented an article of three case presentations, but all with acceptable lung function (which allowed a lung resection, i.e., FEV1 over 55\%), but all on a postoperative background of neoplastic context. Patients had developed aspergillus forms on the remaining pleural cavities, probably air contaminated postoperatively by parenchymal or bronchial air fistulas.

The major element of clinics that imposed a cavernostomy were small-mild, recurrent hemoptysis, less often a massive episode (30-33,38-43).

Concerning surgical timing, Gebitekin et al (44) and Da Silva et al (36) performed the intervention in conditions of massive hemoptysis, but it is preferable to perform the intervention in chronic conditions, if possible, after bronchial artery embolization or after medical treatment with traxemic acid. Rergkliang et al did the cavernostomy for massive hemoptysis, but without having a preoperative pulmonary functional evaluation $(44,45)$.

Cavernostomy is performed where the lesion is closest to the chest wall. The place of incision is the axillary area in most cases, but there was also one case in which the anterior area on the right medioclavicular line was the elected incision area.

In our group, out of 4 surgical procedures, 3 cavernostomies were performed in the right axillary area and one interscapuleovertebral on the left hemithorax after resection of the posterior rib arches 3 and 4 . The procedure itself is guided by the peripheral area of the cavern, usually associated with lesions of the posterior and apical segments. The approach is limited in the scapular area if there is an exact overlap.

It is preferable to locate via guidance the peripheral contact area of the cave under a computed tomography or radioscopic.

The procedure is performed in a single stage under general anesthesia. Performing the procedure under local or regional anesthesia constitutes an exception. Gebitekin et al (44) simultaneously mobilized muscle flaps to fill the cavity. This option should be maintained if there are no major bronchial fistulas. Large flap muscles of the pectoralis major, serratus anterior or latissimus dorsi muscles can be used depending on the topography of the cavern. Shirahashi et al (46) reported a case of two-stage operation with omentopexy following cavernostomy, for lung abscess arising in the residual lung after bilobectomy.

The procedure may also involve mobilization of muscle flaps for filling the remaining cavity, but usually these should be avoided until the area is granulated and the fistulas have shrunk or even closed. It can be carried out later, after the closure of the bronchial fistulas or partially to favor the closure of the fistulas in case of reintervention for the reopening of the stoma. Regnard et al (47) and Sagawa et al (48) mentioned reinterventions to reopen the superficially closed stoma to restore communication.

Postoperatively, the authors mention the dressing of the cavernostoma with gauzes soaked with amphotericin B; however, daily dressing and cleaning the cavernostoma with sterile gauzes is sufficient, abolishing the favorable conditions for fungus development. Systemic antifungal treatment is recommended to precede the intervention by 2 weeks and to follow it for up to 3 months.

Many authors reported a mortality rate higher than that seen with pulmonary resection, but that is because the patients eligible for cavernostomy have a poor general condition or impaired pulmonary function (41-49).

In a large study, Cesar et al (35) presented 111 cases subjected to cavernostomy for pulmonary aspergillosis associated with reduced lung function. The evolution of the patients was similar to the group in which lung resection was performed. The author found a higher rate of hemorrhagic complications, probably due to specific hypervascularization and recurrences, secondary to the tendency of superficial closure of the stoma or complete non-drainage of the aspergillary cavities (35).

Overall, the method of cavernostomy remains a good solution. It is effective and it can be performed in patients with complex fungal ball with peripheral location, with permanently or temporarily impaired pulmonary function. In stable patients without active hemoptysis, it demonstrated to be an easy-to-perform and low-risk procedure.

In conclusion, lung resection techniques for invasive pulmonary aspergillosis are of choice if lung function allows for it and there are no other contraindications. The high rate of mortality of lung aspergillosis with poor ventilator function despite medical treatment and arterial embolization demand a solution with minimal impact. Thus, cavernostomy should remain an option in selected cases that do not allow large-scale resections or an additional functional decrease.

\section{Acknowledgements}

Professional editing, linguistic and technical assistance performed by Irina Radu, Individual Service Provider, certified translator in Medicine and Pharmacy (certificate credentials: Series E no. 0048).

\section{Funding}

No funding was received.

\section{Availability of data and materials}

All data generated or analyzed during this study are included in this published article.

\section{Authors' contributions}

$\mathrm{CP}, \mathrm{AC}, \mathrm{AG}, \mathrm{AZ}$, and CS performed the surgical procedure. $\mathrm{NB}, \mathrm{CS}, \mathrm{MD}, \mathrm{IB}, \mathrm{OS}, \mathrm{SC}$, and DC reviewed and analyzed the literature data. $\mathrm{CD}$ performed the preoperative investigation 
the patient. IB, NB and CS prepared the draft of the manuscript. CS was advisor of the surgical procedures. CS and NB reviewed the final version of the manuscript. CP and CS assessed the authenticity of all data. The authors read and approved the final version of the manuscript.

\section{Ethics approval and consent to participate}

Written informed consent was signed by the patient on 13.05.2020. Approval of the Ethics Committee of 'Marius Nasta' National Institute of Pneumology, Bucharest, Romania was obtained (no 152/2020).

\section{Patient consent for publication}

Consent for publication of the patient's data and images was obtained.

\section{Competing interests}

The authors declare that they have no competing interests.

\section{References}

1. Kousha M, Tadi R and Soubani AO: Pulmonary aspergillosis: A clinical review. Eur Respir Rev 20: 156-174, 2011.

2. Kosmidis C and Denning DW: The clinical spectrum of pulmonary aspergillosis. Thorax 70: 270-277, 2015.

3. Davidsen JR, Rosenvinge FS, Assing K and Laursen CB: Chronic pulmonary aspergillosis. Ugeskr Laeger 180: V05170434, 2018 (In Danish).

4. Patterson KC and Strek ME: Diagnosis and treatment of pulmonary aspergillosis syndromes. Chest 146: 1358-1368, 2014.

5. Denning DW, Cadranel J, Beigelman-Aubry C, Ader F, Chakrabarti A, Blot S, Ullmann AJ, Dimopoulos G and Lange C; European Society for Clinical Microbiology and Infectious Diseases and European Respiratory Society: Chronic pulmonary aspergillosis: Rationale and clinical guidelines for diagnosis and management. Eur Respir J 47: 45-68, 2016.

6. Wilopo BAP, Richardson MD and Denning DW: Diagnostic aspects of chronic pulmonary aspergillosis: Present and new directions. Curr Fungal Infect Rep 13: 292-300, 2019.

7. Denning DW, Follansbee SE, Scolaro M, Norris S, Edelstein H and Stevens DA: Pulmonary aspergillosis in the acquired immunodeficiency syndrome. N Engl J Med 324: 654-662, 1991.

8. Gefter WB: The spectrum of pulmonary aspergillosis. J Thorac Imaging 7: 56-74, 1992.

9. Binder RE, Faling LJ, Pugatch RD, Mahasaen C and Snider GL: Chronic necrotizing pulmonary aspergillosis: A discrete clinical entity. Medicine (Baltimore) 61: 109-124, 1982.

10. Greenberger PA, Bush RK, Demain JG, Luong A, Slavin RG and Knutsen AP: Allergic bronchopulmonary aspergillosis. J Allergy Clin Immunol Pract 2: 703-708, 2014

11. Page ID, Byanyima R, Hosmane S, Onyachi N, Opira C, Richardson M, Sawyer R, Sharman A and Denning DW: Chronic pulmonary aspergillosis commonly complicates treated pulmonary tuberculosis with residual cavitation. Eur Respir J 53 : 1801184,2019

12. Horvat T, Savu C, Motaş C and Teţu M: Pneumopericardium-complication of an unknown tuberculosis in a HIV positive patient. Eur J Cardiothorac Surg 26: 1043, 2004.

13. Walsh TJ, Anaissie EJ, Denning DW, Herbrecht R, Kontoyiannis DP, Marr KA, Morrison VA, Segal BH, Steinbach WJ, Stevens DA, et al: Treatment of aspergillosis: Clinical practice guidelines of the infectious diseases society of America. Clin Infect Dis 46: 327-360, 2008

14. Shibuya K, Ando T, Hasegawa C, Wakayama M, Hamatani S, Hatori T, Nagayama T and Nonaka H: Pathophysiology of pulmonary aspergillosis. J Infect Chemother 10: 138-145, 2004.

15. Ohba H, Miwa S, Shirai M, Kanai M, Eifuku T, Suda T, Hayakawa $\mathrm{H}$ and Chida $\mathrm{K}$ : Clinical characteristics and prognosis of chronic pulmonary aspergillosis. Respir Med 106: 724-729, 2012
16. Soubani $\mathrm{AO}$ and Chandrasekar $\mathrm{PH}$ : The clinical spectrum of pulmonary aspergillosis. Chest 121: 1988-1999, 2002.

17. Zmeili OS and Soubani AO: Pulmonary aspergillosis: A clinical update. QJM 100: 317-334, 2007.

18. Izumikawa K, Tashiro T, Tashiro M, Takazono T, Kosai K, Morinaga Y, Kurihara S, Nakamura S, Imamura Y, Miyazaki T, et al: Pathogenesis and clinical features of chronic pulmonary aspergillosis-is it possible to distinguish CNPA and CCPA clinically? J Infect Chemother 20: 208-212, 2014.

19. Savu C, Melinte A, Posea R, Galie N, Balescu I, Diaconu C, Cretoiu D, Dima S, Filipescu A, Balalau C and Bacalbasa N: Pleural solitary fibrous tumors-a retrospective study on 45 patients. Medicina (Kaunas) 56: 185, 2020.

20. Bruce RA: A case of pulmonary aspergillosis. Tubercle 38: 203-209, 1957.

21. Campbell JH, Winter JH, Richardson MD, Shankland GS and Banham SW: Treatment of pulmonary aspergilloma with itraconazole. Thorax 46: 839-841, 1991.

22. Farid S, Mohamed S, Devbhandari M, Kneale M, Richardson M, Soon SY, Jones MT, Krysiak P, Shah R, Denning DW and Rammohan K: Results of surgery for chronic pulmonary aspergillosis, optimal antifungal therapy and proposed high risk factors for recurrence-a national centre's experience. J Cardiothorac Surg 8: 180, 2013.

23. Jhun BW, Jeon K, Eom JS, Lee JH, Suh GY, Kwon OJ and Koh WJ: Clinical characteristics and treatment outcomes of chronic pulmonary aspergillosis. Med Mycol 51: 811-817, 2013.

24. Stevens DA, Kan VL, Judson MA, Morrison VA, Dummer S, Denning DW, Bennett JE, Walsh TJ, Patterson TF and Pankey GA: Practice guidelines for diseases caused by asperillus. Infectious diseases society of America. Clin Infect Dis 30: 696-709, 2000.

25. Flückiger U, Marchetti O, Bille J, Eggimann P, Zimmerli S, Imhof A, Garbino J, Ruef C, Pittet D, Täuber M, et al: Treatment options of invasive fungal infections in adults. Swiss Med Wkly 136: 447-463, 2006.

26. Munk PL, Vellet AD, Rankin RN, Müller NL and Ahmad D: Intracavitary aspergilloma: Transthoracic percutaneous injection of amphotericin gelatin solution. Radiology 188: 821-823, 1993.

27. Suen H, Wright C and Mathisen DJ: Surgical management of pulmonary aspergillosis. Chest Surg Clin N Am 3: 671-681, 1993.

28. Hargis JL, Bone RC, Stewart J, Rector N and Hiller FC: Intracavitary amphotereicin B in the treatment of symptomatic pulmonary aspergillomas. Am J Med 68: 389-394, 1980.

29. Giron J, Poey C, Fajadet P, Sans N, Fourcade D, Senac JP and Railhac JJ: CT-guided percutaneous treatment of inoperable pulmonary aspergillomas: A study of 40 cases. Eur J Radiol 28: 235-242, 1998 .

30. Kasprzyk M, Pieczynski K, Mania K, Gabryel P, Piwkowski C and Dyszkiewicz W: Surgical treatment for pulmonary aspergilloma-early and long-term results. Kardiochir Torakochirurgia Pol 14: 99-103, 2017.

31. Nakada T, Akiba T, Inagaki T, Morikawa $\mathrm{T}$ and Ohki T: Simplified cavernostomy using wound protector for complex pulmonary aspergilloma. Ann Thorac Surg 98: 360-361, 2014.

32. Gao Y and Soubani A: Advances in the diagnosis and management of pulmonary aspergillosis. Adv Respir Med 87: 231-243, 2019.

33. Lee JG, Lee CY, Park IK, Kim DJ, Chang J, Kim SK and Chung KY: Pulmonary aspergilloma: Analysis of prognosis in relation to symptoms and treatment. J Thorac Cardiovasc Surg 138: 820-825, 2009.

34. Vergeret J, Dabadie P, Dupon M, Maurette P, Taytard A and Chevais R: Endocavitary drainage (Monaldi's technic) in the treatment of pulmonary abscess. Rev Fr Mal Respir 11: 201-207, 1983 (In French)

35. Cesar JM, Resende JS, Amaral NF, Alves CM, Vilhena AF and Silva FL: Cavernostomy x resection for pulmonary aspergilloma: A 32-year history. J Cardiothorac Surg 6: 129, 2011.

36. Da Silva P, Marsico GA, Araujo MA, Braz FS, Santos HT, Loureiro GL and Fontes A: Complex pulmonary aspergilloma treated by cavernostomy. Rev Col Bras Cir 41: 406-411, 2014 (In English, Portuguese).

37. Kelley WO and Pecora DV: The Monaldi procedure; a report of thirty cases. Am Rev Tuberc 65: 83-87, 1952.

38. Ratermann KL, Ereshefsky BJ, Fleishaker EL, Thornton AC, Buch KP and Martin CA: Fulminant invasive pulmonary aspergillosis after a near-drowning accident in an immunocompetent patient. Ann Pharmacother 48: 1225-1229, 2014.

39. Chen JC, Chang YL, Luh SP, Lee JM and Lee YC: Surgical treatment for pulmonary aspergilloma: A 28 year experience. Thorax 52: 810-813, 1997 . 
40. Kilman JW, Ahn C, Andrews NC and Klassen K: Surgery for pulmonary aspergillosis. J Thorac Cardiovasc Surg 57: 642-647, 1969.

41. Massard G, Roeslin N, Wihlm JM, Dumont P, Witz JP and Morand G: Pleuropulmonary aspergilloma: Clinical spectrum and results of surgical treatment. Ann Thorac Surg 54: 1159-1164, 1992.

42. Takahashi R, Fujiwara T and Yamakawa H: Cavernostomy for pulmonary aspergillosis associated with destroyed lung after surgery for lung cancer: Report of 3 cases. Case Rep Surg 2015: 614795, 2015.

43. Soltanzadeh H, Wychulis AR, Sadr F, Bolanowski PJ and Neville WE: Surgical treatment of pulmonary aspergilloma. Ann Surg 186: 13-16, 1977.

44. Gebitekin C, Sami Bayram A and Akin S: Complex pulmonary aspergilloma treated with single stage cavernostomy and myoplasty. Eur J Cardiothorac Surg 27: 737-740, 2005.

45. Rergkliang C, Chetpaophan A, Chittithavorn V and Vasinanukorn P: Surgical management of pulmonary cavity associated with fungus ball. Asian Cardiovasc Thorac Ann 12: 246-249, 2004
46. Shirahashi K, Iuchi K, Matsumura A, Tanaka H, Tamura M and Goto M: A case of two-stage operation, omentopexy following cavernostomy, for lung abscess arising in the residual lung after bilobectomy. J Japan Assoc Chest Surg 17: 691-696, 2003.

47. Regnard JF, Icard P, Nicolosi M, Spagiarri L, Magdeleinat P, Jauffret B and Levasseur P: Aspergilloma: A series of 89 surgical cases. Ann Thorac Surg 69: 898-903, 2000.

48. Sagawa M, Sakuma T, Isobe T, Sugita M, Waseda Y, Morinaga H and Iuchi K: Cavernoscopic removal of a fungus ball for pulmonary complex aspergilloma. Ann Thorac Surg 78: 1846-1848, 2004.

49. Jewkes J, Kay PH, Paneth M and Citron KM: Pulmonary aspergilloma: Analysis of prognosis in relation to haemoptysis and survey of treatment. Thorax 38: 572-578, 1983.

(c) () $\ominus$ This work is licensed under a Creative Commons (c) $\mathrm{EY}$ No ND Attribution-NonCommercial-NoDerivatives 4.0 International (CC BY-NC-ND 4.0) License. 